\title{
Estatuto da forma cê: clítico ou palavra?
}

Liliane Pereira Barbosa

\section{Resumo}

O fato de investigações considerarem cê um clítico pronominal sintático e a constatação da possibilidade de esta forma aparecer em posições em que um clítico não aparece fizeram-nos questionar o seu caráter. Assim, baseados em dados extraídos da literatura atestada e publicada, além de construções do dialeto do Norte de Minas, constatamos, fundamentados na teoria da Cliticização e na Fonologia Prosódica, que cê se comporta não como clítico, mas como palavra plena. Ademais, propusemos, ancorados, ainda, na Fonologia Prosódica, que a atonicidade percebida em cê está no nível da frase e não da palavra. Nesse viés, a sua ausência de tonicidade ocorre em razão da possibilidade de alternância de proeminência acentual no nível da frase entoacional, que, por se relacionar a aspectos semânticos, sintáticos e de desempenho do falante, determina nó forte ou fraco a cê, ou seja, sua posição forte ou fraca na sentença.

Palavras-chave: forma cê; clítico; palavra fonológica; Fonologia Prosódica; Cliticização. 


\section{INTRODUÇÃO}

Considerando a grande produtividade, atualmente, entre os falantes do Português do Brasil - PB -, das formas pronominais alternantes você/ocê e cê, aliada ao fato de a gramática normativa não se pronunciar sobre essa última forma, pois a considera não padrão (estigmatizada), e a análise proposta por Vitral na qual afirma que o cê é clítico sintático, entre as variáveis citadas, determinamos a forma cê como nosso objeto de estudo e nos propomos a fazer um recorte de seu uso no tempo atual e investigar seu estatuto no PB.

Pelo fato de a posição do clítico em Português Europeu (PE) ser sensível à informação prosódica, segundo Frota e Vigário (1996), e de supormos o mesmo para o Português Brasileiro, estabelecemos a seguinte hipótese: assim como alta frequência de ocorrência, velocidade de fala (rápida) e estilo mais informal (fala espontânea) favorecem o processo de redução de itens (BYBEE, 2001) - fato que ocorreu com o pronome você, que se reduziu a cê-, estes dois últimos aspectos, acrescidos de informação semântica, não favorecem alternância do padrão acentual de cê em constituinte prosódico superior à $\omega$ (palavra fonológica)? Ou seja, o c $\hat{e}$ não seria uma palavra plena (e, portanto, não clítico, conforme proposta de Vitral) que surge em contextos e nível prosódico específicos, ora como elemento fraco, ora forte?

A partir do uso do cê em estilo informal pelos falantes do PB (e com velocidade de fala rápida) pretendemos: a) analisar se a forma reduzida cê se comporta nesta língua como clítico pronominal (sintático e/ou fonológico), dentro do quadro da Cliticização; b) conferir o status de palavra plena cê, tanto dentro do aparato da Cliticização quanto da Fonologia Prosódica; c) propor uma análise alternativa para a atonicidade percebida em cê fundamentada em pressupostos teóricos da Fonologia Prosódica; d) contribuir com uma reflexão sobre os clíticos no PB, enfocando os aspectos sintáticos, morfológicos e fonológicos destas formas, uma vez que constituem tema controverso entre os estudiosos que por elas se interessam, e e) dialogar com outros textos que abordam o mesmo assunto. Em suma, nossa proposta é demonstrar que $c \hat{e}$ não é clítico sintático, mas palavra plena.

\section{Revisita à literatura}

Como nosso objeto de estudo é um pronome, nesta seção revisitamos essa categoria gramatical e os pressupostos das propostas teóricas nas quais nos ancoramos. 


\subsection{Sobre os pronomes}

A literatura atesta que a Língua Portuguesa do Brasil possui um elenco de pronomes pessoais clíticos em distribuição complementar com suas formas plenas correspondentes (algumas dessas formas plenas, ao longo dos tempos, passaram por reenquadramentos), cuja distribuição é bem diferente do PE, pois enquanto em PE as regras de posição de próclise e ênclise são bem definidas, em PB há prevalência da posição proclítica (PEREIRA, 1981). Dados também confirmam que o PB não segue a Lei de Wackernagel ${ }^{2}$ e nem a de Tobler Mussafia ${ }^{3}$, pois há no PB clíticos iniciando sentenças, distribuição sintática não permitida em PE.

Ambos os dialetos do Português Brasileiro e do Europeu possuem padrões bem definidos quanto à posição ocupada pelos clíticos. Alguns autores como Duarte (1986) atualmente defendem a ideia de que os clíticos acusativos em PB estão sendo anulados, optando-se, em seu lugar, pela variante OD nulo, NP lexical ou pronome tônico.

\subsection{Cliticização}

Clítico é um termo que denomina as formas que se assemelham a palavras, mas que não podem aparecer sozinhas em um enunciado normal, sendo estruturalmente dependentes fonológica ou sintaticamente de uma palavra vizinha (hospedeiro). Assim sendo, a cliticização expressa a ligação do clítico com um elemento hospedeiro, a qual será, nesta investigação, observada segundo

2 Lei Wackernagel: Jakob Wackernagel observou que em línguas indo-européias os elementos clíticos geralmente aparecem em segunda posição nas orações, embora, primeiramente, tenha identificado clíticos como elementos tipicamente sem acento, formas prosodicamente dependentes.

3 Lei de Tobler Mussafia: pronomes átonos não podem ocupar a posição inicial em sentenças.

4 Adotamos o termo mista para denominar esta terceira abordagem pelo motivo dos estudiosos, por nós selecionados para fundamentar o trabalho, divergirem quanto à análise dos clíticos. Spencer, Zwicky e Klavans optam pelo prisma morfossintático-fonológico e Galves e Abaurre, pelo prisma sintático-fonológico. abordagens sintáticas, fonológicas e/ou morfológicas, já que elas auxiliarão na definição do status atual da forma cê.

A descrição dos clíticos sintáticos, segundo a literatura transformacional, nos indicará suas propriedades, mas destacamos também os enfoques de Kayne (1975) e Sportiche (1992; 1993; 1995) por considerarmos que suas posições corroboram as de nossa proposta, razão de surgirem destacados. Para a análise fonológica utilizamos o enfoque de Nespor e Vogel (1986) e, por fim, para uma análise mista ${ }^{4}$, adotamos autores como Spencer (1991), Klavans (1982; 1985), Zwicky (1985), Galves e Abaurre (1996). No quadro 2), a seguir, apresentamos uma síntese dessas abordagens. 
QUADRO 2 - Síntese das propostas para clíticos

\begin{tabular}{|c|c|}
\hline \multicolumn{2}{|r|}{ Propostas } \\
\hline \multicolumn{2}{|r|}{ Abordagem sintática } \\
\hline $\begin{array}{l}\text { Literatura } \\
\text { transformacional }\end{array}$ & $\begin{array}{l}\text { Objetos clíticos estão em distribuição complementar com objetos NPs plenos; clítico em } \\
\text { Romance é adjungido ao V lexical e o complexo todo contém categoria V, podendo ser } \\
\text { elevado de sua posição inicial. } \\
\text { Análises divergentes para a categoria vazia surgida com a elevação: } \\
\text { a) Aoun: clítico ocupa posição não argumental; b) Borer: clítico assume posição argu- } \\
\text { mental do NP, mas não absorve Caso; c) Jaeggli: clítico assume posição argumental do } \\
\text { NP, absorve Caso e cv deve ser pro. }\end{array}$ \\
\hline Kayne & $\begin{array}{l}\text { Sua análise para os clíticos é a mesma da literatura transformacional. Propõe testes } \\
\text { sintáticos para atestar o caráter clítico de uma forma. }\end{array}$ \\
\hline Sportiche & $\begin{array}{l}\text { Este autor não opta pela análise de que clítico substitui NP (DP), nem por movimento } \\
\text { de clíticos ou que clíticos são gerados em posição artificial. } \\
\text { Para ele, clíticos ocorrem adjungidos ao elemento mais alto da oração que contém XP } \\
\text { e clíticos pronominais de sujeito não são clíticos sintáticos, apenas clíticos fonológicos, } \\
\text { que assumem a posição de núcleo de NP e não de DP. }\end{array}$ \\
\hline \multicolumn{2}{|r|}{ Abordagem fonológica } \\
\hline Nespor e Vogel & $\begin{array}{l}\text { Clíticos nunca ocorrem sozinhos e não podem receber acento contrastivo. As autoras } \\
\text { corroboram três testes fonológicos de Zwicky. }\end{array}$ \\
\hline \multicolumn{2}{|r|}{ Abordagem mista } \\
\hline Spencer & $\begin{array}{l}\text { Clíticos atam-se fonologicamente a hospedeiros, são incapazes de receber acento (exceto } \\
\text { grego) e sua posição depende da acentuação da sentença ou fatores prosódicos similares. } \\
\text { Atam-se mais a um elemento prosódico que a um sintático, podendo ser de dois tipos: } \\
\text { a) aqueles que parecem ter a mesma função morfossintática que palavras plenas; b) } \\
\text { aqueles que não parecem corresponder a formas plenas. }\end{array}$ \\
\hline Klavans & $\begin{array}{l}\text { Propõe uma teoria unificada - parametrização dos clíticos: P1(dominância): inicial/ } \\
\text { final; P2(precedência): antes/depois; P3(liaison): próclise/ênclise (P1 e P2 são parâme- } \\
\text { tros sintáticos e P3 fonológico). } \\
\text { Clíticos podem ter um hospedeiro fonológico e um sintático independentes. Domínio } \\
\text { da Cliticização: S ou N' (exceto para línguas românicas cujo domínio é V). }\end{array}$ \\
\hline Zwicky & $\begin{array}{l}\text { Considera dois clíticos: } \\
\text {-clítico simples: forma ditada pela frase fonológica; } \\
\text {-clítico especial: forma alomorfe separada da forma plena, que não é derivada de } \\
\text { processos de redução de frase fonológica. } \\
\text { Propõe testes fonológicos e sintáticos para se distinguir clítico de palavra inde- } \\
\text { pendente. }\end{array}$ \\
\hline Galves e Abaurre & $\begin{array}{l}\text { Distinguem clíticos sintáticos e fonológicos, sendo estes mais amplos que aqueles } \\
\text { e não totalmente condicionados pela sintaxe. Clíticos sintáticos são núcleos de sin- } \\
\text { tagmas e os fonológicos são parte integrante da palavra em que se ancoram. }\end{array}$ \\
\hline
\end{tabular}

Pelo exposto no quadro 2, percebe-se que há abordagens para cliticização que sugerem que tal fenômeno é, provavelmente, analisado como um fenômeno sintático, mas algumas reforçam a 
necessidade de uma operação fonológica e morfológica para seu desvendamento.

\subsection{Fonologia prosódica}

Desenvolvida como uma reação contra os conceitos de fonologia gerativa padrão, que tinha como características uma organização linear de segmentos e um conjunto de regras cujos domínios de aplicação eram definidos segundo uma interface sintaxe e fonologia (sistema fonológico homogêneo), a Fonologia Prosódica - teoria da interação entre fonologia e os demais componentes da gramática (sintaxe, morfologia e semântica) - propõe que a representação mental da fala é dividida hierarquicamente em chunks organizados e cada constituinte prosódico serve de domínio de aplicação de regras fonológicas específicas, além de obter diferentes tipos de informação fonológica e não fonológica, não necessariamente isomórficos, na definição de seus domínios.

Esse modelo apregoa que alguns fenômenos fonológicos dependem de sua relação sintática, morfológica e/ou semântica para operarem e lidarem com regras de mapeamento que agrupam os elementos terminais de um nó, criando unidades que não necessariamente estão em uma relação um-a-um com os constituintes da hierarquia morfossintática. Tais unidades constituem os domínios de aplicação de regras fonológicas que fazem uso de diferentes tipos de noções gramaticais em cada nível da hierarquia.

São sete os constituintes da hierarquia prosódica, segundo Nespor e Vogel (1986), contudo nos referimos, em nossa pesquisa, apenas à $\omega, C, \phi$ e $I$, cujas regras de mapeamento incorporam informações morfológicas $(\omega)$, sintáticas $(C, \phi$ e $I)$ e semânticas $(I)$.

Essa relação entre constituintes e informação linguística se dá em razão de diferentes tipos de fenômenos se referirem à hierarquia prosódica, que inclui não apenas processos fonológicos, mas também fenômenos rítmicos, duracionais, entoacionais e de proeminência, podendo haver discordância entre estrutura

5 Refere-se à parte dos estudos da língua que analisa o processo por meio do qual os itens se tornam mais gramaticais através dos tempos, focalizando como formas e construções gramaticais surgem e como são usadas (HOPPER e TRAUGOTT, 1993).

6 Segundo Hopper e Traugott apud Vitral e Ramos (1999), a etapa de cliticização apresenta duas propriedades: perda de autonomia lexical (dependência contextual) e significação mais geral. fonológica e morfossintática, isto é, enquanto a estrutura sintática é fixa, a estrutura fonológica pode variar de acordo com fatores como velocidade de fala, extensão (tamanho) dos constituintes prosódicos.

\section{PROPOSTA DA FORMA CÊ COMO CLÍTICO}

A proposta de Vitral (1996), fundamentada na noção de gramaticalização ${ }^{5}$, é de que cê comporta-se como clítico pronominal sintático com especialização na posição sintática de sujeito préverbal. Esse estudioso defende que cê passa por uma das etapas desse processo de gramaticalização: a cliticização ${ }^{6}$. Segundo sua abordagem, um elemento lexical que passa por esse processo de gramaticalização apresenta perda de expressividade e enfraque- 
7 Há formas intermediárias entre as etapas descritas em (48): vosmecê entre a $1^{\mathrm{a}}$ e a $2^{\mathrm{a}}$ etapas; ocê entre a $2^{\mathrm{a}}$ e $3^{\mathrm{a}}$ etapas e essas etapas descritas foram extraídas de Vitral (1996).

8 Para esse propósito, foi tomada parte do corpus do trabalho variacionista de COELHO (1999), a quem agradecemos, como material investigativo, desconsiderando-se suas formas combinadas (docê/ducê $($ de $+o c \hat{e})$, procê/prucê/ pucê $($ pratocê), socê/sucê (se+ocê), concê/cuncê/cucê $($ com + ocê $)$, quecê/quicê $(q u e+c \hat{e})$, socê $($ só $+o c \hat{e})) \mathrm{e}$ vocêis.

9 A tabela 2 de Coelho (1999, p. 56) deixa evidente essa preferência sintática das formas você/ocê/cê. cimento da forma fonológica e do significado lexical, podendo tornar-se cada vez mais gramatical. Vitral (1996) analisa a forma $c \hat{e}$ sob esse aspecto em razão de, segundo as transformações ocorridas ao longo do tempo, ter sido um pronome lexical (Vossa Mercê) e de hoje se apresentar como forma gramatical.

(1) item lexical: Vossa Mercê > item gramatical: você > clítico: cê > afixo flexional ${ }^{7}$

A proposta de Vitral de que cê é clítico fundamenta-se em vários dados analisados. Esse estudioso alega que a forma cê: a) especializou-se na posição de sujeito (pré-verbal), não ocorrendo em posições deslocadas (sentenças topicalizadas, focalizadas, sujeito posposto), nem sozinha em enunciados ou coordenada e modificada; b) é clítico sintático nominativo em estágio inicial, razão de surgir interpolada, ou seja, haver elementos lexicais entre a forma cê e o verbo; c) caracteriza redução fonológica de você, que se tornou um item mais gramatical com o passar dos tempos, sofrendo enfraquecimento do significado lexical da forma fonológica; d) possui características fonéticas como duração e intensidade, de acordo com seus dados, muito próximas de se.

\section{ANÁLISE DE CÊ COMO CLÍTICO}

Vitral (2001b) observa que, numa abordagem tradicional, $a$ atonicidade desses elementos [clíticos] condiciona a distribuição sintática deles, mas isso viria como uma consequência de serem átonos, que seria assim, o traço definitório desses itens. Assim, anteriormente à discussão de sua análise, reavaliamos o comportamento fonológico de cê descrito por Coelho (1999)', que incluiu, em sua análise, formas combinadas, as quais optamos por desconsiderar.

Coelho (1999), em análise, concluiu que a forma cê ocorre, preferencialmente, antecedida de pausa, enquanto as demais formas, de vogal; verificou, também, que cê ocupa preferencialmente a posição sintática de sujeito (assim como as demais formas).

\subsection{A forma cê é [um] clítico?}

Nesta subseção, avaliamos cada argumento de Vitral, que propõe ser o cê clítico nominativo sintático com a finalidade de lhe conferir status e para comprovar ou refutar essa análise.

Primeiro Argumento: especialização sintática da forma cê na posição de sujeito (pré-verbal).

Relacionamos esse argumento de especialização sintática da forma cê na posição de sujeito (pré-verbal) à análise variacionista de Coelho (1999) que constata ser a forma cê mais frequente em função de sujeito.

Porém, em Coelho (1999), fica também evidente que as formas você/ocê preferem essa mesma posição"; logo, esta não é uma característica exclusiva da forma cê, uma vez que é compartilhada por suas outras variáveis. Além disso, esse ambiente sintático 
também pode ser ocupado por palavras lexicais. Isso quer dizer que o fato de cê ocupar tipicamente esta posição sintática não é suficiente para classificá-la como clítico, ou seja, não se poderia considerar que cê se alocou na posição de sujeito para se realizar como clítico (posição propícia a clítico para se agregar ao verbo), já que palavras plenas podem ocupar este mesmo lugar.

Mesmo assim, buscamos confirmar a especialização proposta por Vitral, mas constatamos no Norte de Minas Gerais a ocorrência de cê em ambientes sintáticos não considerados (e até mesmo tidos como agramaticais) por Vitral (2002), ambientes estes característicos de elementos fortes. Há na região citada emprego da forma de cế:

a) em posição pós-verbal:

(1) Eu vi cê na festa ontem posposto ao verbo:

(2) Foi $c \hat{e}$ o culpado de tudo. preposto:

(3) $C \hat{e}$, ele não viu nascer.

d) coordenado com constituinte similar:

(4) Cê e Pedro podem votar contra, eu não me importo.

e) modificado por advérbio:

5) Apenas cê sabe como tudo aconteceu, mais ninguém.

f) tópico:

(6) Cês, eu acho que cês não passaram, não.

g) foco contrastivo:

(7) - Maria, nós vamos comprar esse livro.

- Cê vai, eu não. Eu já o conheço e não gosto nadinha dele.

h) resposta:

(8) - Pode deixar que vou resolver isso pra você.

- Cê??? (risos)

Esses ambientes variados de ocorrência de cê corroboram a análise de que é forma forte.

Segundo Argumento: a forma cê é um clítico sintático em estágio inicial no processo de cliticização.

Segundo Vitral (2002), a forma cêé um novo clítico que trilha os estágios iniciais do processo de cliticização, assemelhando-se aos clíticos do período medieval, pois, nesse período, era recorrente a não estrita adjacência entre clítico e hospedeiro e, embora 
os clíticos atuais não compartilhem essa característica - exigem adjacência estrita ao seu elemento hospedeiro -, o mesmo ocorre com a forma $c \hat{e}$, já que entre esse elemento e o verbo, seu suposto hospedeiro, vários elementos podem ser intercalados.

Acontece que 1) a opção pela não interpolação não era marginal no português medieval (VITRAL, 2002). Há, mesmo em contextos favoráveis à interpolação, opção pela não interpolação, conforme se pode comprovar abaixo:

(9) como aqui se comtem. (1522)

(10) que não se Laura. (1510)

No caso da forma $c \hat{e}$, contudo, sabemos que, quando há elementos interpolados, esta opcionalidade não existe:

(11) Cê já foi ao mercado?

* Já cê foi ao mercado?

Verificamos que sua interpolação é obrigatória (11), inclusive já mencionada por Vitral (2002), e atinge até mesmo o nível oracional (12), em que se constata um grande distanciamento entre cê e o verbo do qual é o argumento externo:

(12) Cê, que é filho de Deus, saberá o que fazer quando chegar a hora.

*Que é filho de Deus, cê saberá o que fazer quando chegar a hora.

Comparamos o fato de cê não admitir não interpolação, em ambientes em que há elementos interpolados, com o fato de os clíticos medievais admitirem essa não interpolação (embora preferissem a interpolação); concluímos que $c \hat{e}$, na atualidade, não se encontra no mesmo estágio dos clíticos medievais, porque se assim fosse compartilhariam também essa característica (o que não impede que isso venha a ocorrer).

Reforça-se ainda que, segundo a literatura, o clítico ocorre contíguo ao seu hospedeiro, sendo a interpolação uma característica de palavras plenas. Então, o fato de surgirem elementos interpolados entre cê e o verbo é indício de que, nessas construções, cê não é clítico; nesses casos, a forma cê é elemento forte. Essa característica de a forma cê surgir em interpolação levanta um questionamento: Terá a forma cê status ambíguo dependendo do contexto, isto é, será elemento forte quando aparece em ambiente de interpolação e elemento fraco quando não há interpolação? Acreditamos que não e, por isso, propomos uma análise que consideramos adequada, conforme veremos posteriormente.

Vitral (2002) também verificou que 2) apesar de cê admitir essa "interpolação", não exibe a segunda característica dos clíticos medievais: não ocorrência em $1^{a}$ posição. Pelo contrário, corroborando Vitral, a análise fonológica atesta que cê ocupa, tipicamente, a posição precedida de pausa, isto é, a $1^{\mathrm{a}}$ posição, ou seja, cê não 
segue as Leis de Wackernagel e de Tobler Mussafia como os clíticos medievais.

Com essas características não é possível se definir um ponto no processo de cliticização em que $c \hat{e}$ poderia encontrar-se, porque essa forma não se comporta como os clíticos medievais (ela ocorre tipicamente como primeiro elemento da sentença e a interpolação, quando surgem elementos, é obrigatória) e nem como os clíticos atuais, pois cê admite interpolação, quando surgem elementos entre ela e o verbo ${ }^{10}$.

Consideramos que, no período medieval, quando as interpolações eram recorrentes e preferenciais, os atuais pronomes átonos da Língua Portuguesa não eram clíticos, assim como $c \hat{e}$ não o é; trilhavam possivelmente um estágio anterior do processo de gramaticalização.

Terceiro Argumento: o pronome você, com o passar dos tempos, sofreu redução fonológica e se tornou mais gramatical (enfraquecimento de significado).

Este terceiro argumento deixa evidente a proposta de Vitral, em seu trabalho com Ramos (1999), de que, com o passar do tempo, você sofreu enfraquecimento de seu significado e já atingiu o status de expletivo, enquanto sua forma reduzida cê apresenta apenas perda de referência virtual. Essa análise é intrigante, porque a noção de gramaticalização pressupõe que a forma reduzida deve apresentar, nesse tipo de fenômeno, maior gramaticalidade (perda de conteúdo semântico) do que a forma plena. Na realidade, esses estudiosos constatam que o inverso ocorreu entre você e $c \hat{e}$, isto é, você apresenta maior gramaticalidade que $c \hat{e}$, contrariando a noção. Para corroborar essa posição dos autores, estendemos a esta análise exemplos de $c \hat{e}^{11}$ com o mesmo suposto uso expletivo de você:

10 Mesmo sendo especulação, será que, tentando-se definir um ponto no processo de gramaticalização, a forma cê não estaria num período anterior ao medieval, já que neste período o fenômeno de interpolação entre os atuais pronomes oblíquos átonos e o verbo era variável (+/-) e no período contemporâneo é categórica a não-interpolação (-)? Levando-se em conta a Teoria Variacionista (LABOV, 1972), que prevê variação antes de mudança, será que antes do período medieval a interpolação entre esses elementos não era categórica $(+)$ ? Assim: $(+) \quad(+/-) \quad(-)$

11 Construções gramaticais do dialeto norte-mineiro. (13a) Em Buenos Aires cêf/você tem confeitarias.

(14) Em Kioto cêf/você tem aquela confusão nas ruas.

Questionamos se estas formas você/cê são realmente expletivas, porque isto implica que, em $\mathrm{PB}$, há formas expletivas e que o verbo é impessoal, conforme essa análise. E sabe-se que, em PB, não há evidências da existência de formas expletivas até então. Por outro lado, o verbo ter é usado, em nossa língua, com o mesmo valor semântico de haver.

Porém, construções como Em Buenos Aires cê há confeitarias não são recorrentes na PB. Acreditamos, na verdade, que a proposta de Viotti (2003) na qual alega que ter é um verbo leve, isto é, esvaziado semanticamente e com predicativo enfraquecido, podendo, portanto, construir uma multiplicidade de sentenças de significados diferentes, cujo significado é resultado da composição do sentido dos vários itens lexicais que compõem a sentença, seja mais interessante. 
Essa proposta faz-nos postular que o verbo "ter" poderia imantar-se de sentido pessoal, não de "possuir", mas de "poder gozar de", "encontrar", "dispor de", justificando a presença de você/ $c \hat{e}$ com uso indeterminado, indefinido nas sentenças abordadas. Dessa maneira, preservamos a intuição dos falantes norte-mineiros que atestam as formas você/cê nestes ambientes com significado de "a gente", "as pessoas", como em:

(13b) Em Buenos Aires você/cê pode gozar de confeitarias.

(13c) Em Buenos Aires você/cê encontra confeitarias.

(13d) Em Buenos Aires você/cê dispõe de confeitarias para ir...

Em relação a este argumento, consideramos pertinente a gramaticalização diagnosticada por Vitral nas formas você e cê, mas não há indícios suficientes para se afirmar que você tenha atingido o status de expletivo e nem que cê já atingiu a etapa de cliticização (nem mesmo o estágio inicial, conforme proposta de Vitral). Estas formas possuem emprego definido e indefinido alternantes, de acordo com o uso dos falantes do norte de Minas, diagnosticado nos dados de Coelho (1999).

Quarto Argumento: características fonéticas (duração e intensidade) da forma cê são muito próximas de se.

Este quarto argumento baseia-se no experimento fonético de Vitral (2001b), que teve por finalidade examinar se a forma $c \hat{e}$ se aproxima foneticamente, em intensidade (I) e duração (D), de se. A análise concluiu que as duas primeiras formas são clíticos e que a forma Zé é tônica, mas, considerando-se a análise absoluta, esse experimento registra gradação de valores, conforme resultado a seguir:

SE: I: $23,6 \mathrm{~dB}$

CÊ: I: $26,3 \mathrm{~dB}$

ZÉ: I: $31,3 \mathrm{~dB}$

D: $0,129 \mathrm{~ms}$

D: $0,138 \mathrm{~ms}$

D: 0,194 $\mathrm{ms}^{12}$

Porém, é necessário considerar que a altura da língua das vogais de cê e Zé atesta diferença de intensidade e duração no português do Brasil - possibilidade esta descartada por Vitral, uma vez que considera que a distinção entre Zé e cê não deve ser atribuída à intensidade das vogais envolvidas.

Além disso, fenômenos entoacionais e de proeminência relacionados à velocidade de fala, informações semânticas (foco, tópico) e estilo de fala informal também podem gerar variação da estrutura fonológica e possibilitar que um mesmo chunk se realize com proeminência acentual distinta, conforme demonstra

12 Resultado, em números absolutos, extraído de Vitral (2001b). o exemplo a seguir: em (15a) a $1^{\text {a }}$ frase fonológica apresenta nó forte; em (15b), o nó forte está na $2^{\mathrm{a}}$ frase fonológica; e, em (15c) o nó forte está na $3^{\text {a }}$ frase fonológica. 
(15a) $[[[[$ [Zé ] $\omega] C] \phi[[$ [ num pensô] $\omega] C] \phi \quad[$ [ [que terminaria $] \omega] C] \phi] I$

$\mathbf{S}$
$\mathbf{W}$

$(15 b)[[[[Z e ́] \omega] C] \phi[[$ [num pensô] $\omega] C] \phi \quad[$ [ [que terminaria $] \omega] C] \phi] I$

$\mathbf{W}$

$\mathbf{S}$

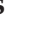

w

$\mathbf{w}$

(15c) $[$ [ [ [ Zé ] $\omega] C] \phi[[$ [ num pensô] $\omega] C] \phi \quad[$ [ [que terminaria $] \omega] C] \phi] I$

$\mathbf{W}$

W

$\mathbf{s}$

Com base no resultado desse experimento e a partir dos questionamentos levantados, a forma cê não pode ser considerada clítico.

\section{TESTANDO O COMPORTAMENTO DE CÊ}

A partir de nossas reflexões descritas acima, optamos por aplicar testes de identificação de clíticos tanto na perspectiva da teoria da Cliticização quanto da Fonologia Prosódica, conforme a seguir, para verificar o status da forma cê.

\subsection{Sob a perspectiva da Cliticização}

Em razão dos inúmeros questionamentos que permeiam este trabalho, propomo-nos a analisar se o pronome cê se comporta como clítico sintático e a avaliar seu estatuto atual, segundo os testes de Zwicky (1985) e Kayne (1975), uma vez que almejam à identificação de clíticos distinguindo-os de palavras plenas através de suas características fonológicas, morfológicas e sintáticas.

\section{Testes fonológicos}

Os testes fonológicos de Zwicky (1985) indicam o comportamento do elemento investigado, atentando-se à sua formação no constituinte prosódico palavra fonológica. Ou melhor, caso apareça um elemento hospedeiro na palavra fonológica que domine $c \hat{e}$, nosso objeto de estudo será clítico; porém, se este constituinte prosódico for não-ramificado, cê é palavra plena porque dispensará hospedeiro.

O clítico forma com uma palavra plena uma palavra fonológica:

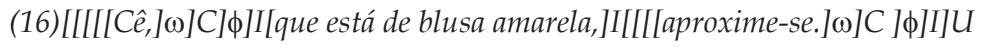

Em (16) temos três frases entoacionais cuja organização prosódica é justificada pelo fato de orações relativas explicativas 
formarem seu próprio domínio entoacional. Nesse exemplo, o pronome cê é uma única palavra plena (possui um acento primário) que forma uma palavra fonológica; esta forma uma unidade prosódica superior: grupo clítico. Este grupo clítico forma uma frase fonológica não ramificada (formada apenas por uma única palavra fonológica) que, por sua vez, constitui uma frase entoacional. Como o clítico pronominal se ancora num elemento hospedeiro verbal, é impossível analisar cê como clítico, pois não há este elemento hospedeiro necessário no grupo clítico e nem no constituinte prosódico imediatamente superior: frase fonológica.

Já na terceira frase entoacional de (16) podemos constatar que se é clítico, pois se ancora no elemento verbal aproxime e ambos constituem uma palavra fonológica formada de clítico+verbo. Esta análise é corroborada por Zwicky (1985), quando salienta a importância dos domínios prosódicos na identificação de clítico e de palavra plena: se o elemento descrito possui seus traços prosódicos (acento, p.e.) distribuídos na frase fonológica é palavra plena; mas se seus traços prosódicos estão distribuídos no domínio da palavra fonológica, este elemento é clítico.

\section{Testes acentuais}

Devido ao fato de clíticos carecerem do acento de seu hospedeiro (dependência acentual) por serem formas átonas, estes testes (ZWICKY, 1985) também colaboram na identificação do status de $c \hat{e}$.

(17) Foi cê o culpado de tudo

(18) Foi-se o culpado de tudo.

Através da contraposição entre os sintagmas foi cê (17) e foi-se (18) verificamos, mediante a atonicidade do pronome clítico se, que não há semelhança acentual entre cê e se. Pelo contrário, este par salienta a tonicidade acentual de $c \hat{e}$, ratificando o teste anterior, pois em (17) tanto o verbo quanto cê possuem acento primário independente, constituindo duas palavras plenas distintas.

Testes usando similaridades entre afixos flexionais e clíticos

Estes testes (ZWICKY, 1985) também auxiliam na identificação dos clíticos, já que se comportam como afixos flexionais de uma palavra plena.

Segundo o teste de ligação, elementos que estão unidos a um hospedeiro são clíticos.

(19) - Pode deixar... eu resolvo este problema pra você. - Cê?!...(risos)

Embora, aparentemente, cê pareça não figurar sozinha em um enunciado, conforme atestam dados de Vitral (2002), há contex- 
tos que favorecem sua figuração isolada (19). Esta possibilidade é determinada por contextos influenciados pela entoação e fatores prosódicos similares; uma entoação própria da surpresa, dúvida, deboche ou incredulidade parecem favorecê-la.

Porém, essa impossibilidade de figurar sozinha em um enunciado não ocorre apenas com palavras átonas; é confirmada em palavras tônicas, conforme Vigário (2001), o que torna esse critério insuficiente para classificar cê como clítico.

Também, a posição de Nespor e Vogel (1996), quando afirmam que clíticos nunca ocorrem sozinhos, reforça a classificação de $c \hat{e}$ como palavra plena, já que esta forma figura sozinha em determinados contextos, assim como palavras tônicas.

Elementos que preservam combinações serão clíticos, segundo o teste do fechamento.

(20) Cê viu Maria?

(21) Cê jamais viu Maria?

(22) Cê, que viaja tanto, jamais viu Maria?

(23) Cê certamente nunca mais verá Maria.

(24) Cê e eu jamais veremos Maria.

(25) Vi cê na festa ontem.

(26) Cê, que já tá pra ganhar neném e tem problema de pressão alta, deve repousá bastante.

Estes dados comprovam as variadas combinações possíveis de $c \hat{e}$ e atestam seu status de palavra plena, pois, conforme Zwicky (1985), se um elemento tem habilidade para se combinar com frases e muitas palavras, certamente é palavra plena.

A ordem dos elementos também é importante, pois, assim como os morfemas adjacentes, os clíticos não possuem liberdade de alterarem sua ordem (certos clíticos exibem alguma liberdade, mas causam mudança de significado cognitivo), podendo permanecer apenas proclíticos ou enclíticos ao seu hospedeiro.

(27a) Eu acho que cês não passaram de ano, não.

(27b) Cês, eu acho que não passaram de ano, não.

O deslocamento de cês em (27b) para a posição inicial de sentença não acarretou mudança semântica. A possibilidade desse deslocamento sem gerar alteração de seu significado cognitivo classifica cê como palavra plena. Também, a distribuição de um elemento colabora na sua identificação como palavra plena ou clítico, pois os clíticos possuem distribuição simples: um único princípio governa sua distribuição (teste da distribuição), assim como os afixos flexionais. Os dados a seguir demonstram distribuições possíveis de $c \hat{e}$ : 
Cê combinada com NP lexical (nominativos pré-verbal):

(28) Cê e João serão felizes juntos.

Cê (nominativo pré-verbal) combinada com V':

(29) Cê comeu o bolo?

Cê (nominativo pós-verbal) combinada com V:

(30) Vi cê na festa ontem.

Cê combinada com CP:

(31) Cê, que é a preferida, receberá uma gratificação.

Cê combinada com NP lexical (acusativos):

(32) Verei cê e João na festa sábado.

Os clíticos também não demonstram complexidade morfológica (raramente possuem dois ou mais morfemas); as palavras sim, apresentam maior complexidade.

(33) $C \hat{e}\left\{\right.$ pronome $\left\{2^{\mathrm{a}}\right.$ pessoa $\}$ singular $\}$

O pronome $c \hat{e}$ (33) possui três morfemas, podendo ser enquadrado entre as palavras plenas. Mas vale ressaltar que essa complexidade morfológica é compartilhada por clíticos de $3^{\mathrm{a}}$ pessoa em PB; como exemplo temos o pronome oblíquo átono $a$ que possui quatro morfemas: (34) a \{pronome\} $\left\{3^{a}\right.$ pessoa\} \{feminino\} \{singular\}

\section{Testes sintáticos}

Como o clítico não está sujeito a processos sintáticos, em razão de sua fixidez em relação ao seu hospedeiro, o elemento que não for imune a tais processos será palavra plena. No caso de um de dois elementos $x+y$ poder ter sua identidade oculta, ambos serão palavras plenas (apagamento sob identidade):

(35a) Eu vou à festa e cê vai também.

(35b) Eu vou à festa e cê, também.

O apagamento sob identidade do verbo foi possível (35b) nos elementos cê vai (35a); logo, ambos são palavras plenas.

A substituição de um dos dois elementos combinados por outro os caracteriza como palavras plenas. E essa substituição foi possível com um pronome tônico e até com um NP lexical:

(36) Duas horas e cê só falou isso agora!

(37) Duas horas e $\boldsymbol{t} u$ só falou isso agora!

(38) Duas horas e Gisele só falou isso agora!

O movimento de apenas um dos dois elementos combinados também os caracteriza como palavras plenas. O deslocamento de $c \hat{e}$, em (39a) para a posição inicial da sentença (39b) comprova 
a possibilidade de cê mover-se isoladamente, logo independe do outro elemento; então, ambos são palavras plenas.

(39a) Eu acho que cês não passaram de ano, não.

(39b) Cês, eu acho que não passaram de ano, não.

Como nada intervém entre clítico e verbo, então, se entre cê e o verbo vários elementos podem ser interpolados, conforme (40), esta forma não é clítica.

\section{(40) Cê nunca mais me verá.}

Também, o fato de os clíticos não poderem ser modificados e a presença de modificadores em (41b) não corroboram que cê seja clítico, pelo contrário:

(41a) Cêé o mais sem-vergonha.

(41b) De todos, cê só é o mais sem-vergonha.

Quanto ao teste que se refere à impossibilidade de clítico aparecer unido por conjunção, este não é também aplicável, pois em (42) e (43) temos cê coordenado a um NP lexical e a um pronome tônico, respectivamente; $\mathrm{e}$, se somente coordenamos elementos de mesma hierarquia (paralelismo), então cê não é clítico.

(42) Cê e Joaquina vão viajar juntas.

(43) Cê e ele serão felizes.

Por fim, ao se determinar que clítico não pode ser topicalizado, atesta-se que cê não é clítico, é palavra plena, porque esta forma pode surgir como tópico: (44) Cês, eu acho que cês não passaram de ano, não.

Essa análise realizada resulta na classificação de cê como palavra plena e não clítico (sintático e/ou fonológico). Os resultados, tanto dos testes de Zwicky (1985) quanto de Kayne (1975) ${ }^{13}$, reforçam o status de palavra plena da forma cê e descartam a hipótese de clítico fonológico e/ou sintático, visto que os critérios de análise consideraram os aspectos fonológicos, morfológicos e sintáticos.

Mesmo que o teste de ligação comprove que cê geralmente

${ }^{13}$ Cardinaletti e Starke (1994) corroboram três critérios de Kayne ao afirmarem que apenas pronomes fortes aparecem coordenados, ocupam posição sintática periférica e são acompanhados por modificadores. Assim como Nespor e Vogel (1986), também consideram que apenas palavras acentuadas (pronomes fortes) suportam acento contrastivo. não figura sozinha em qualquer enunciado, apenas em contextos influenciados por determinada entoação e outros fatores prosódicos, nossa análise não se enfraquece, pois este fator não ocorre apenas com palavras átonas, também é confirmado em palavras tônicas, conforme Vigário (2001). O fato de cê ocorrer sozinha já descarta a possibilidade de ser clítico, segundo Nespor e Vogel (1986) - para essas estudiosas, clítico nunca ocorre sozinho em enunciados. A revelação de que há em PB pronomes átonos que possuem maior complexidade morfológica que cê é outro aspecto que também não prejudica nossa proposta já que, assim como $c \hat{e}$, temos palavras acentuadas com menor complexidade morfológica 
que os pronomes átonos de nossa língua (por exemplo, as palavras aquilo, nada, tudo).

Em razão do resultado dos testes realizados nesta seção, defendemos que cê possui caráter acentuado (acento de palavra), mas pode sofrer perda acentual no nível da frase entoacional uma análise alternativa para justificar sua atonicidade em algumas construções, que consideramos mais adequada do que lhe fornecer um status ambíguo.

\subsection{Sob a perspectiva da Fonologia Prosódica}

Visto que cê é palavra com acento primário, como se comprovou através de testes sintáticos, morfológicos e fonológicos propostos pela teoria da cliticização (seção anterior), corroboramos seu caráter; porém, sob uma abordagem prosódica. Isso se torna possível em razão de apenas palavras plenas poderem constituir, sozinhas, prosodicamente, uma palavra fonológica não ramificada.

Fundamentando-nos em Selkirk (2004), quando defende que palavras funcionais podem adquirir status de palavra fonológica, e em Bisol (2000), que atesta e comprova a existência de palavras fonológicas monossílabas em $\mathrm{PB}^{14}$, partimos da hipótese de que $c \hat{e}$ também aí se enquadra. Para confirmar tal hipótese, valemo-nos de palavras do PB que possuem a mesma estrutura, mas que se distinguem apenas pela tonicidade/atonicidade:

\begin{tabular}{cc}
\hline $\begin{array}{c}\text { (38) Palavras monossílabas } \\
\text { acentuadas }\end{array}$ & $\begin{array}{c}\text { Palavras monossílabas } \\
\text { não acentuadas }\end{array}$ \\
\hline dê [Ède] & de [dZI] \\
nu [Ènu] & no [nU] \\
dá [Èda] & da $[\mathrm{d} \ll]$ \\
\hline
\end{tabular}

E cê também aqui se enquadra:

14 Vigário (2001) afirma que em PE também há palavras fonológicas monossílabas.
Palavras monossílabas não acentuadas se $[\mathrm{sI}]$

Desta distribuição, constata-se que as formas acentuadas constituem $\omega$, mas as formas não acentuadas (clíticas) precisam de um hospedeiro acentuado para que façam parte de uma $\omega$, porque isoladas não a constituem.

(46) $[[C \hat{e}] \omega] C[[$ se viu $] \omega] C[$ [no espelho.] $\omega] C$ 
As $2^{\mathrm{a}}$ e $3^{\mathrm{a}}$ palavras fonológicas de (46) demonstram a dependência dos clíticos em relação a seus hospedeiros; porém a $1^{a}$ palavra fonológica comprova a ocorrência de cê sem hospedeiro, logo não pode ser clítico. Para reforçar esta classificação, Vigário (2001) afirma que a presença de acento impossibilita a ocorrência de processos fonológicos que se aplicam a ambientes não acentuados:

- é impossível redução vocálica:

$$
\begin{aligned}
& \text { (47) dê [e]/*[i] de [e]/ [i] } \\
& \text { cê [e]/ *[i] se [e]/ [i] }
\end{aligned}
$$
vogal:

- é impossível semivocalização ou apagamento da $1^{\mathrm{a}}$ ou $2^{\mathrm{a}}$

$$
\text { (48) cê ia }[\mathrm{e}] /{ }^{*}[\mathrm{i}] /{ }^{*} 0 \text { se una }[\mathrm{e}] /[\mathrm{I}]
$$

Se um desses processos se aplica à palavra monossílaba, constitui evidência de que a palavra relevante não é acentuada e, por isso, carece de status de palavra fonológica. Não é o caso da forma $c \hat{e}$, pois, conforme demonstrado acima, nenhum dos processos foi aplicado a ela.

Vigário (2001) também verificou, em PE, que a presença de um acento tonal (ou focal) pode ser vista como meio de demonstrar o status acentuado de uma dada palavra e o mesmo ocorre com cê em PB:

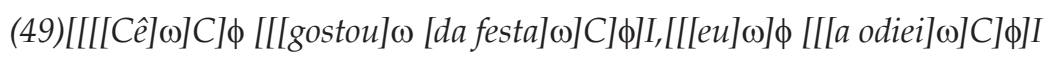

$$
\mathbf{s}
$$

$\mathbf{W}$

$\mathbf{w}$

$\mathbf{W}$

$\mathbf{W}$

Ao cê formar a frase fonológica mais proeminente da primeira frase entoacional (49) e, dessa proeminência, provocar foco contrastivo, comprovamos que $c \hat{e}$ ocorre em posição acentual forte; logo, não pode ser elemento clítico, afirmativa também em concordância com Hall (1999a), que defende a ocorrência de foco contrastivo como teste identificador de palavra com acento primário. O mesmo ocorre em (50) e (51).

$$
\begin{array}{cc}
\text { (50) - Maria, cê foi na festa ontem? (51) - Gê, cê adorou a festa, né? } \\
\text { - Cê foi, eu não. }
\end{array}
$$

Como defendemos a ideia de que cê não é clítico nem mesmo nas construções em que apresenta fraca intensidade, em razão dos vários e fortes indícios sintáticos, morfológicos e fonológicos descritos ao longo desse trabalho, propomos que a palavra plena cê pode adquirir ou não acento frasal, dependendo de padrões prosódicos específicos e do contexto no qual estiver inserida. 
Major (1985) observa que um acento no nível da palavra pode ser alterado no nível da sentença, isto é, padrão rítmico do nível da sentença pode alterar padrão rítmico do nível da palavra para acomodar uma tendência acentual. Acreditamos que isso explique a fraca intensidade de $c \hat{e}$ em alguns contextos.

Defendemos também o ponto de vista de que a teoria de domínios de aplicação de regras fonológicas e não fonológicas (não necessariamente isomórficas) nos apontará regras rítmicas e de ajustamentos rítmicos que são importantes para o processamento da fala (NESPOR e VOGEL, 1986) da forma cê, pois, enquanto a estrutura sintática é única, a estrutura fonológica pode variar dependendo de fatores como velocidade da fala (VIGÁRIO, 2001), estilo de fala e desempenho do falante. Acreditamos que esta forma, em uma unidade prosódica acima da palavra fonológica, pode sofrer perda acentual com proeminência em outro elemento ou sintagma, de acordo com o contexto.

Como em posição de sujeito simples cê é frase fonológica não ramificada, não podendo passar por reestruturação, porque em PB há fronteira de frase fonológica entre sujeito e predicado, conforme Sândalo ([2002]), tal forma constitui nó forte neste contexto, o que é confirmado em (52):

(52) $[$ Cê $] \phi[$ sabe $] \phi[$ muito bem $] \phi[$ do que eu gosto. $] \phi$

$$
\begin{array}{lllllllll}
\mathrm{S} & \mathrm{S} & \mathrm{W} & \mathrm{S} & \mathrm{W} & \mathrm{W} & \mathrm{W} & \mathrm{S}
\end{array}
$$

Na posição de complemento verbal, poderá constituir junto com o verbo uma frase fonológica ramificada, através de reestruturação, como em (53):

(53) $[$ Foi cê] $] \phi[$ que eu vi na festa. $] \phi$

W S

Será o nó mais forte porque, em frase fonológica, o elemento mais à direita é o mais proeminente, e cê está nesta posição na $1^{a}$ frase fonológica da sentença acima. Porém, analisando a frase entoacional, hierarquia acima da frase fonológica, verificamos que cê pode assumir padrões de proeminência diferentes. Isso ocorre em razão de a frase entoacional, formada de uma ou mais frases fonológicas, ser uma unidade prosódica que possui variabilidade na sua organização, conforme explicitado anteriormente.

Os exemplos (54) podem assumir três padrões de proeminência acentual diferentes para as frases fonológicas que constituem I, conforme distribuição a seguir:

(54a) [ [ [ [ Cêe ] $\omega] C] \phi[[$ [ o conhecê $] \omega] C] \phi[$ [ [ muito bem $] \omega] C] \phi] I^{15}$

${ }^{15}$ Nó forte está na frase fonológica "muito bem"; as demais constituem nó fraco.
W $\quad$ W

(54b) $[[[[$ Cê $] \omega] C] \phi[[$ o conhecê $] \omega] C] \phi \quad[[[$ muito bem $] \omega] C] \phi] I^{16}$
W

W 
(54c) $[[$ [ [ Cê ] $\omega] C] \phi[[$ [ o conhecê $] \omega] C] \phi[[$ [ muito bem $] \omega] C] \phi] I^{17}$

W

$\mathrm{S}$

W

O primeiro e o último exemplo dessa série de padrões de proeminência exploram formação fraca para a frase fonológica $c \hat{e}$, com proeminência acentual alternante em outra frase fonológica da mesma I; mas o segundo exemplo representa cê como uma frase fonológica da I, com proeminência forte. Este exemplo explora formação não ramificada para cê, já que esta frase fonológica está representada por um grupo clítico formado de apenas um elemento: uma palavra fonológica. Esta mesma formação deixa evidente a ausência do suposto hospedeiro para cê e reforça o seu caráter acentual; consequentemente, esta forma não pode ser considerada clítico, mas palavra plena.

Essas descrições prosódicas de cê favorecem a identificação de proeminência acentual alternante no nível da sentença, de acordo com o desempenho do falante. Percebe-se que a palavra plena cê sofre perda acentual no nível da sentença (no constituinte prosódico frase entoacional) em determinados ambientes, recebendo acento fraco. Isso não quer dizer que perdeu seu acento de palavra, mas apenas que não recebeu acento frasal. Outros ambientes são indicadores de sua presença com acento forte, também no nível da sentença (no constituinte frase entoacional), conforme discutido nesta seção.

\section{CONCLUSÃO}

Nesta investigação, detectaram-se ocorrências de cê em posições que não constituem ambientes de clíticos. Esses fatos aliados à obrigatoriedade de interpolação, quando entre cê e o verbo surgem outros elementos, a aspectos fonológicos, morfológicos e sintáticos não propícios a clítico revelados pelos testes de Zwicky (1985) e de Kayne (1975) - testes tidos como identificadores de clítico -, serviram de subsídios para refutar a análise de Vitral, conferindo-se e comprovando-se o status de palavra plena a cê e, consequentemente, a impossibilidade de ela ser clítico sintático.

Mas, como era nossa proposta investigar seu caráter acentual, fundamentando-nos em pressupostos teóricos da Fonologia Prosódica, valemo-nos da existência de palavras funcionais monossilábicas acentuadas. A impossibilidade de redução e de semivocalização ou apagamento da vogal (neste último caso, quando cê está seguido de palavra iniciada por vogal), conjugada à possibilidade de apresentar acento tonal ou focal, proeminência

16 Nó forte está na frase fonológica "cê", as demais constituem nó fraco.

17 Nó forte está na frase fonológica "o conhece", as demais constituem nó fraco. acentual forte, no constituinte frase entoacional, reafirmaram nossa expectativa, pois acento é fator que impede sândi vocálico, e apenas palavras que possuem acento primário recebem acento frasal.

Acrescentando-se, ainda, o fato de constituir frase fonológica não ramificada quando em posição de sujeito, constituinte 
imediatamente superior ao grupo clítico, e à impossibilidade de reconstrução, já que entre sujeito e predicado em PB é sempre encontrada uma fronteira prosódica, postulamos o status de palavra plena a $c \hat{e}$.

Devido a essa constatação também num aparato prosódico, questionamos por que percebemos uma perda acentual dessa forma em algumas construções e decidimos observar seu comportamento em um nível hierárquico superior à palavra fonológica.

Como frase fonológica, $c \hat{e}$, em posição de sujeito, constitui nó forte de $\phi$ não ramificada; em frase fonológica ramificada, em posição de complemento de verbo, e sendo o elemento mais à sua direita, também é nó forte. Porém, na frase entoacional, nível em que há maior variabilidade do padrão de acento frasal, percebemos que $c \hat{e}$ exibe ora maior, ora menor proeminência.

Assim, o presente estudo advoga que cê possui acento primário, logo é palavra plena (e não clítico), mas que pode apresentar alternância acentual como $\phi$ (fraca/forte) no domínio da I em fala espontânea e informal.

\begin{abstract}
:
The fact that investigations consider 'cế' a syntactically clitic pronoun and the finding that this form may appear in positions in which a clitic does not occur made us question its character. Thus, based on data extracted from attested and published literature beyond constructions of the dialect from the North of Minas Gerais, Brazil, based on the Cliticization theory and Prosodic Phonology, we found out that 'cế' behaves not as a clitic, but as a full word. Besides, we proposed, still based on the Prosodic Phonology, that the perceived stress on 'cê' is at the phrase level, not at the word level. So this stress absence occurs due to the possibility of stress prominence alternance at the intonation phrase level which, due to its relation to semantic, syntactic aspects and speaker performance, determines a strong or weak node to 'c $\hat{e}$ ', that is, its strong or weak position in the sentence.
\end{abstract}

Keywords: 'cê' form; clitic; phonological word; Prosodic Phonology; Cliticization.

\title{
REFERÊNCIAS
}

BARBOSA, Liliane Pereira. Estatuto da forma cê: clítico ou palavra?. Orientador: Seung Hwa-Lee. Dissertação (Mestrado em Estudos Linguísticos) - Faculdade de Letras, Universidade Federal de Minas Gerais, Belo Horizonte. 2005.135p. 
GALVES, Charlotte; ABAURRE, Maria B. M. Os clíticos no português brasileiro: elementos para uma abordagem sintático-fonológica. In: Gramática do português falado. Campinas: Ed. UNICAMP, 1996.

GREEN, A. D. The prosodic structure of Irish, Scots Gaelic and Manx. 1997. PhD dissertation, Cornell University.

HOPPER, Paul J.; TRAUGOTT, Elizabeth C. Grammaticalization. Cambridge: Cambridge University Press, 1993.

KAYNE, R. Romance clitics, verb movement, and PRO. In: Linguistic Inquiry. vol. 22, n. 4. USA: Massachusetts Institute of Technology, 1991.

KLAVANS, Judith L. Some problems in a theory of clitics. Bloomington: Indiana University Linguistics Club, 1982.

NESPOR, Marina; VOGEL, Irene. Prosodic phonology. Dordrecht: Foris Publications, 1986.

SPORTICHE, Dominique. French predicate clitics and clause structure $\mathcal{E}$ subject clitics in French and Romance.[ s.l.: s.n., 1993.]

VITRAL, Lorenzo. A forma cê e a noção de gramaticalização. In: Revista de Estudo da Linguagem. Belo Horizonte: FALE, jan./ jun. 1996.

. Sintaxe formal e gramaticalização: roteiro de pesquisa. In: NICOLAU, Eunice (org). Estudos sobre a Estrutura Gramatical da Linguagem. Belo Horizonte: FALE, 2001a.

. A interpolação de se e suas consequências para a teoria da cliticização. In: Revista da ABRALIN. vol. 1, no 1, 2002.

. Identificando clíticos: evidências fonéticas. Artigo elaborado durante pós-doutoramento no IEL/UNICAMP, 2001b. inédito.

VITRAL, Lorenzo; RAMOS, Jânia M. Gramaticalização de "você": um processo de perda de informação semântica? In: Filologia e Linguística Portuguesa. n. 3, p. 55-63, 1999.

ZWICKY, Arnold M. On clitics. Bloomington: Indiana University Linguistics Club, 1977. 